\title{
Enantiomeric Degradation of 2-(4-Sulfophenyl)Butyrate via 4-Sulfocatechol in Delftia acidovorans SPB1
}

\author{
SASKIA SCHULZ, ${ }^{1,2} \dagger$ WENBO DONG,${ }^{1}+\mathrm{ULRICH}$ GROTH ${ }^{2}$ AND ALASDAIR M. COOK ${ }^{1 *}$ \\ Departments of Biology ${ }^{1}$ and Chemistry, ${ }^{2}$ The University of Konstanz, D-78457 Konstanz, Germany
}

\begin{abstract}
Enrichment cultures with enantiomeric 2-(4-sulfophenyl)butyrate (SPB) as the sole added source(s) of carbon and energy for growth yielded a pure culture of a degradative bacterium, which was identified as Delftia acidovorans SPB1. The organism utilized the enantiomers sequentially. $R$-SPB was utilized first (specific growth rate $[\mu]=0.28 \mathbf{h}^{-1}$ ), with transient excretion of an unknown intermediate, which was identified as 4-sulfocatechol (4SC). Utilization of $S$-SPB was slower $\left(\mu=0.016 \mathrm{~h}^{-1}\right)$ and was initiated only after the first enantiomer was exhausted. Suspensions of cells grown in $S$-SPB excreted 4SC, so metabolism of the two enantiomers converged at $4 \mathrm{SC}$. The latter was degraded by ortho cleavage via 3 -sulfo-cis,cis-muconate. Strain SPB1 grew with 4SC and with 1-(4-sulfophenyl)octane (referred to herein as model LAS) but not with commercial linear alkylbenzenesulfonate (LAS) surfactant, which is subterminally substituted but nontoxic. It would appear that metabolism of the model LAS does not represent metabolism of commercial LAS.
\end{abstract}

One of the major xenobiotic compounds degraded in sewage works worldwide is linear alkylbenzenesulfonate (LAS) surfactant, which has an annual production of about 2,500,000 tons (40). Whereas the degradation of LAS is well established (16, $26,27,35,39,43)$, the mechanisms of its degradation are not (4).

Commercial LAS (Fig. 1) is, ideally, a mixture of linear alkanes $\left(C_{10}\right.$ to $\left.C_{13}\right)$ subterminally substituted with a single 4-sulfophenyl moiety (31): this means a mixture of 20 compounds, 18 of which are racemic mixtures. Although many different degradative reactions have been deduced from the intermediates which have been observed $(38,43)$, the general opinion is that the major degradative pathway involves oxygenation of one or both of the terminal methyl groups by an unknown oxygenase (see also references 19 and 20) followed by rounds of $\beta$-oxidation to yield a large set of transient sulfophenyl(di)carboxylates (Fig. 1) (9, 14, 17, 38, 43, 47, 49). On paper, seven sulfophenyl(di)carboxylates, representing a maximum number of $\beta$-oxidation steps, can be proposed: 2-(4sulfophenyl)butyrate (SPB) (which is often observed during the degradation of commercial LAS [e.g., see reference 14]), 2-(4-sulfophenyl)propionate, 2-(4-sulfophenyl)malonate, 3-(4sulfophenyl)butyrate, 2-(4-sulfophenyl)succinate, 3-(4-sulfophenyl)valerate and 3-(4-sulfophenyl)glutarate.

Many of these sulfophenyl(di)carboxylates are optically active (24), which can be assumed to have consequences for their further degradation $(25,50)$. SPB is quantitatively converted to cell material, $\mathrm{CO}_{2}$, water, and sulfate by activated sludge (27), but none of the degradative mechanisms are known (4).

We now describe the isolation of Delftia acidovorans SPB1, which degrades both enantiomers of SPB via 4-sulfocatechol (4SC) and ortho ring cleavage $(7,13)$.

* Corresponding author. Mailing address: Department of Biology, The University of Konstanz, Universitätstr. 10, D-78457 Konstanz, Germany. Phone: (49) 753188 4247. Fax: (49) 75318829 66. E-mail: Alasdair.Cook@uni-konstanz.de.

$\dagger$ Present address: Sartorius AG, D-37075 Göttingen, Germany.

$\$$ Present address: Department of Environmental Science and Engineering, Fudan University, Shanghai, China.

\section{MATERIALS AND METHODS}

Materials. Racemic, $R$ - and $S$-SPB were synthesized by reacting sulfuric acid with the corresponding phenylcarboxylic acid (45). Yields of about $30 \%$ were obtained at about $97 \%$ purity; the major by-product, 2-(2-sulfophenyl)butyrate, was not totally removed on recrystallization (retention time, about $4 \mathrm{~min}$ [Fig. 2]). The identity of the product was confirmed by electrospray mass spectrometry (MS) and nuclear magnetic resonance. The following mass spectral data were collected in the negative ion mode: $[M-2 \mathrm{H}]^{2-}, m / z 121 ;[M-\mathrm{H}]^{-}, m / z 243$; $\left[M+\mathrm{Na}^{+}-2 \mathrm{H}\right]^{-}, m / z 265 .{ }^{1} \mathrm{H}$ nuclear magnetic resonance measurements gave four sets of peaks with chemical shifts downfield of tetramethylsilane: $0.87 \mathrm{ppm}$ (t, 3H), $\mathrm{CH}_{3}$ (C-4); 1.85 ppm (m, 2H), $\mathrm{CH}_{2}$ (C-3); 3.47 ppm (t, 1H), CH (C-2); $7.6 \mathrm{ppm}(\mathrm{pq}, 4 \mathrm{H})$, aromatic protons indicating para substitution of the sulfonate group (34). Synthetic $R$-SPB was obtained at $96 \%$ purity and an enantiomer excess of $96 \% ; S$-SPB was $96 \%$ pure with an enantiomer excess of $94 \%$.

4SC was kindly supplied at about $95 \%$ purity by B. Feigel (13); the major impurity was 3-sulfocatechol. 3-Sulfocatechol was available from F. Junker (22). The identity of $4 \mathrm{SC}$ was confirmed by electrospray MS in the negative ion mode, where $[M-\mathrm{H}]^{-} m / z 189$ was observed. Commercial LAS (Marlon A 350) was kindly supplied by Hüls, Marl, Germany. The starting materials for the chemical syntheses were purchased from Fluka (Buchs, Switzerland). Other chemicals were from Fluka, Aldrich (St. Louis, Mo.) or Merck (Darmstadt, Germany).

Intermediates in the degradation of LAS, presumably sulfophenylcarboxylates and sulfophenyldicarboxylates (based on their UV spectra), were generated in a laboratory trickling filter during its early stages of use, as indicated elsewhere (27). The eluate from the trickling filter was chromatographed (26), the fractions corresponding to the desired material were collected and subjected to solidphase extraction to remove the perchlorate in the mobile phase (28), and the neutralized material was used in growth medium.

Three sources of inocula were used in the enrichment cultures: activated sludge from the sewage treatment plants in Radolfzell (largely communal wastes), Konstanz (communal and some industrial wastes), and Ludwigshafen (largely industrial wastes), all in Germany.

The reference culture for the degradation of 4SC via ortho ring cleavage is a mixture of Hydrogenophaga palleronii S1 and Agrobacterium radiobacter S2 (18), and each was kindly made available by A. Stolz, University of Stuttgart, Stuttgart, Germany.

Analytical methods. Racemic SPB was initially detected by reversed-phase high-performance liquid chromatography (HPLC) $(8,32)$. When it became clear that a chiral separation was required, we chose a $\beta$-pm-Nucleodex column $(5-\mu \mathrm{m}$ diameter particles; 200-mm column of 4-mm internal diameter; Macherey \& Nagel, Düren, Germany). We found $100 \mathrm{mM}$ potassium phosphate buffer, $\mathrm{pH}$ 6.0 , to give optimal separation and operated the column at $0.5 \mathrm{ml} / \mathrm{min}$ at room temperature (about $23^{\circ} \mathrm{C}$ ). The sample volume did not exceed $50 \mu$ l. The diode array detector was set to give a chromatogram at $220 \mathrm{~nm}$. $R$-SPB eluted at 6.5 min with baseline separation from $S$-SPB (8.4 min) (Fig. 2). The ortho analogues, impurities from the synthesis, eluted at about $4.1 \mathrm{~min}$, whereas $4 \mathrm{SC}$ eluted at 4.5 min (Fig. 2). The standard curve for $R$-SPB, $S$-SPB, or $4 \mathrm{SC}$ was linear to about 40,40 , or $10 \mathrm{nmol} / \mathrm{injection}$, and the limits of detection were about $0.25,0.25$, and $0.05 \mathrm{nmol} /$ injection, respectively. The reproducibility of quantitation (peak area) for the SPB enantiomers was $98.8 \%(n=6)$, and that for 4 SC was $97.2 \%(n=$ $6)$. The retention times at constant temperature varied by $\pm 0.05 \mathrm{~min}$.

Oxygen uptake was measured in a Clarke type oxygen electrode (Rank, Cam- 


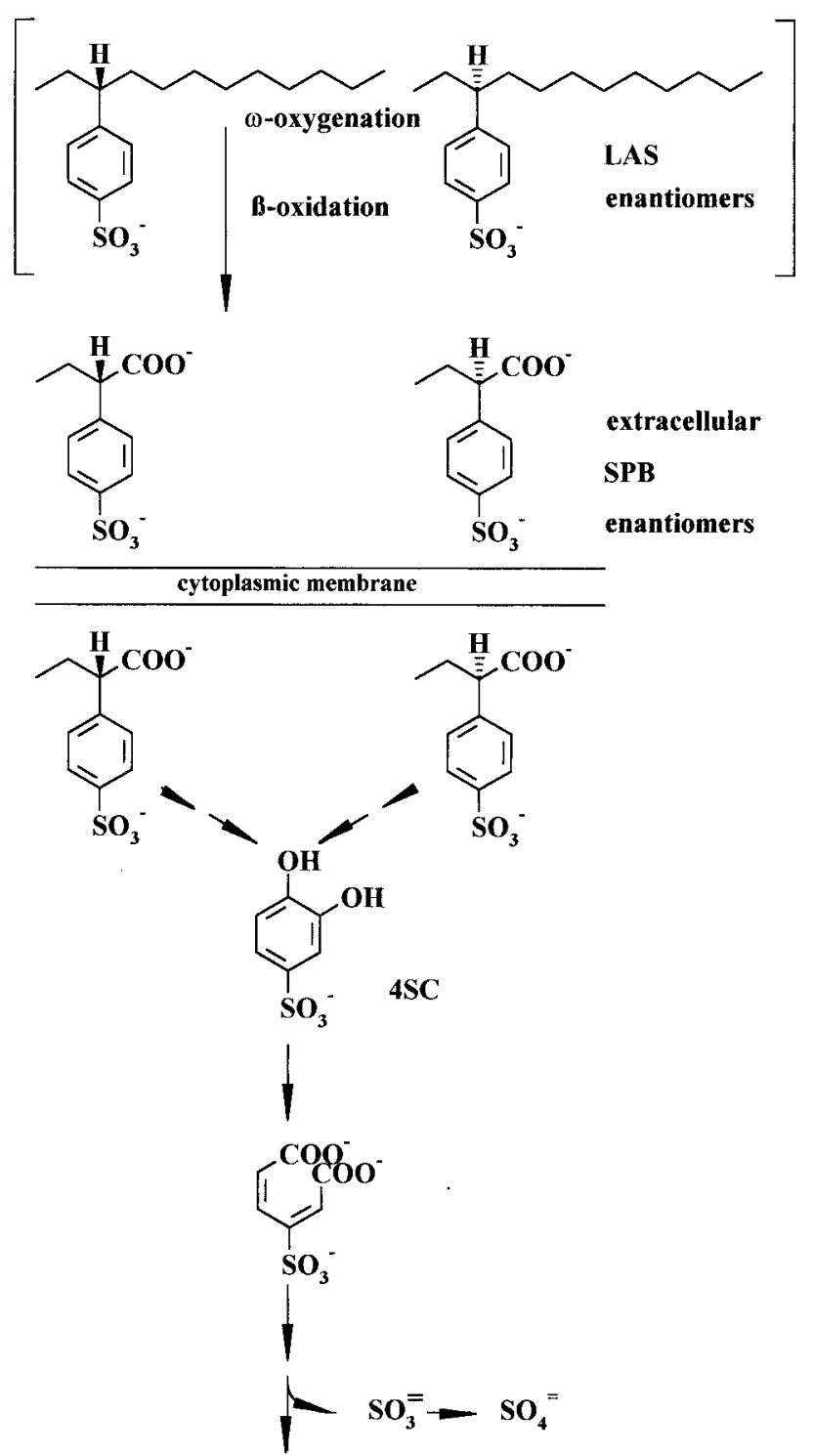

$\mathrm{CO}_{2}$ biomass $\mathrm{H}_{2} \mathrm{O}$

FIG. 1. Presumed major pathway for the conversion of racemic, commercial LAS to racemic sulfophenylcarboxylates, with an example yielding the two enantiomers of SPB, which are converted to $4 \mathrm{SC}$ and subject to ortho ring cleavage and desulfonation by $D$. acidivorans SPB1. The square brackets represent metabolism in another portion(s) of the putative community which degrades commercial LAS $(21,36 a, 41)$. SPB represents one transient intermediate found extracellularly in sewage works, receiving waters, and soil $(9,14,17)$. It is then sensible to anticipate the transport of SPB into the cell, because all sulfonates require transport systems (7). The mechanism of conversion of SPB to 4SC is still unknown. SPB is one of the seven smallest sulfophenyl(di)carboxylates which can be derived from LAS.

bridge, United Kingdom) with a $0.5-\mathrm{ml}$ working volume. Sulfate ion was detected turbidimetrically after precipitation with barium ion (44). Sulfite was detected colorimetrically (29). Protein assay was performed by a Lowry method (6). Dissolved organic carbon was detected in a total organic carbon analyzer (15). Aromatic ring cleavage for taxonomic purposes was deduced by standard methods (42). A partial 16S rRNA gene sequence (450 bp) of strain SPB1 was determined by the German Culture Collection (Deutsche Sammlung von Mikroorganismen und Zellkulturen, Braunschweig, Germany), where the sequence data were aligned and compared as described elsewhere $(33,36)$.

Enrichment cultures and growth of organisms. Aerobic enrichment cultures were set up with inocula from three activated sludges. Cultures $(5 \mathrm{ml})$ in $30-\mathrm{ml}$ screw-cap tubes were incubated at $30^{\circ} \mathrm{C}$ on a roller in the dark. The substrate,

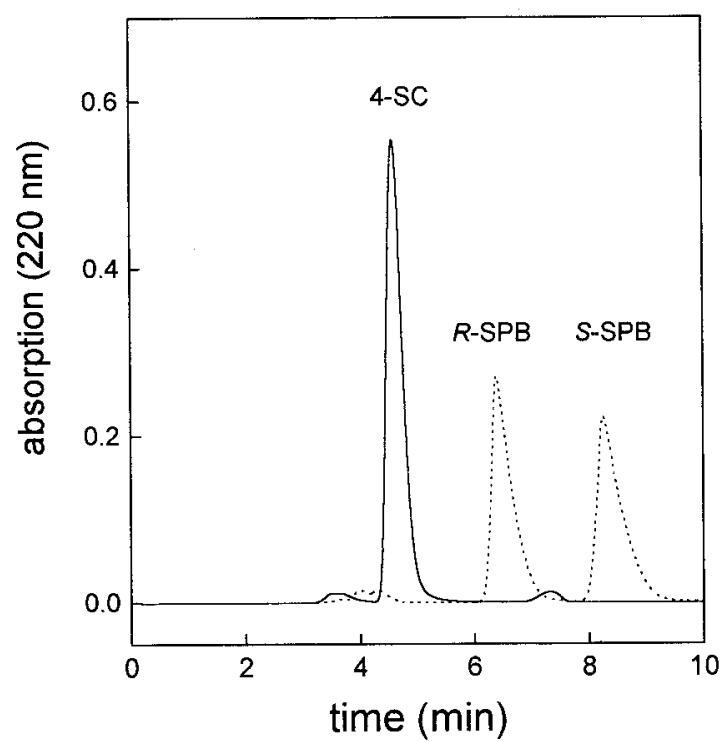

FIG. 2. Separation of $R$ - and $S$-SPB from one another, from traces of the impurity, racemic 2-(2-sulfophenyl)butyrate, and from 4SC.

racemic SPB as the sole source of carbon and energy for growth, was present at $6 \mathrm{mM}$ in a salts medium buffered with $50 \mathrm{mM}$ phosphate, $\mathrm{pH} 7.2$ (46). Cultures were streaked on Plate Count Agar (Difco) after at least three passages in the enrichment medium. Individual colonies were picked and removed to selective liquid medium. Positive cultures were restreaked and subcultured in selective liquid medium. A culture was considered pure when three successive plates were homogeneous and identical. Short-term storage of the organisms was on selective medium solidified with $1.5 \%$ agar as slants at $4^{\circ} \mathrm{C}$. Long-term storage was in $50 \%$ glycerol at $-80^{\circ} \mathrm{C}$. The organism was deposited with the German Culture Collection under the accession no. DSM 12586.

Growth experiments were done routinely in $400-\mathrm{ml}$ cultures in 1-liter flatbottomed, sidearm flasks mounted in a $30^{\circ} \mathrm{C}$ water bath. Aeration was by a magnetically driven stirring bar; sterile air was sparged through a washbottle at $30^{\circ} \mathrm{C}$. Samples were taken at intervals through the side arm. Whole cultures, harvested before the end of growth and washed in $50 \mathrm{mM}$ phosphate puffer, $\mathrm{pH}$ 7.2 (46), were used for the preparation of cell extracts. Growth of cultures utilizing enantiomers of SPB was carried out in 50-ml cultures stirred in 300-ml Erlenmeyer flasks with a sidearm in the form of a test tube; the test tubes fitted a photometer and allowed the optical density to be monitored without sacrificing material. Samples $(1 \mathrm{ml})$, taken at intervals to measure the oxygen uptake of whole cells, were centrifuged $\left(10,000 \times g\right.$ for $5 \mathrm{~min}$ at about $\left.20^{\circ} \mathrm{C}\right)$ and the supernatant fluid was discarded; the cells were resuspended immediately in 0.5 $\mathrm{ml}$ of $50 \mathrm{mM}$ potassium phosphate buffer, $\mathrm{pH} 7.5$, and washed $(10,000 \times g$ for 5 min at about $20^{\circ} \mathrm{C}$ ). The cells were resuspended in fresh potassium phosphate buffer and examined immediately for racemic SPB-, $S$-SPB-, or 4SC-dependent oxygen uptake.

Cultures of strain SPB1 were also grown with $10 \mathrm{mM}$ succinate as the sole source of carbon and energy.

$H$. pallereronii $\mathrm{S} 1$ and $A$. radiobacter $\mathrm{S} 2$ were grown in $3 \mathrm{mM}$ sulfanilate-salts medium (46)

Cell extracts. Cells in the mid-exponential phase of growth with $R$-SPB in the racemic mixture (or sulfanilate) were harvested, washed twice in $50 \mathrm{mM}$ potas-

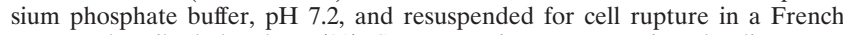
press as described elsewhere (23). Some experiments to monitor the disappearance of $4 \mathrm{SC}$ were done in $1-\mathrm{ml}$ reaction mixtures in a 1-cm light path quartz cuvette in a Uvikon 922 spectrophotometer, and UV spectra from 200 to $400 \mathrm{~nm}$ were taken at intervals. The reaction mixture (13), which contained $0.3 \mathrm{mg}$ of protein (crude extract, supernatant fluid), was buffered with $50 \mathrm{mM}$ Tris- $\mathrm{HCl}, \mathrm{pH}$ 8.0 , and the reaction was started by the addition of $150 \mathrm{nmol}$ of $4 \mathrm{SC}$. In some experiments, samples were taken at intervals and examined by HPLC.

\section{RESULTS}

Enrichment cultures, isolation, characterization, and identification of $D$. acidovorans SPB1. Enrichment cultures for organisms which could utilize racemic SPB (three of five positive) were obtained easily. Growth (turbidity) of the first culture within 1 week was normal, and subcultures usually grew 
overnight. Three mixed cultures, SPB1 (from Radolfzell), SPB2 (from Konstanz), and SPB3 (from Ludwigshafen), were essentially homogeneous (by light microscopy) and comprised largely a single bacterial morphotype with some protozoan grazers. Strain SPB1 was readily isolated from the mixed culture of the same name. Isolation of a bacterium from cultures SPB2 and SPB3 was not achieved.

Strain SPB1 was an aerobic, motile, oxidase-positive, catalase-positive, gram-negative rod, which usually occurred in pairs. There was ortho cleavage of protocatechuate. Analysis of the sequence of the 16S rRNA gene indicated $99 \%$ identity with $D$. acidovorans, which is in agreement with the simple taxonomic tests done.

Growth characteristics of $\boldsymbol{D}$. acidovorans SPB1. Preliminary growth experiments in racemic SPB-salts medium were done with suboptimal aeration. The culture developed a transient pink or purple color for several hours, during which time the $R$ enantiomer disappeared. The $S$ enantiomer then largely disappeared without significant growth. The coloration was interpreted as the iron complex of a catechol (12), and chromatography on the chiral column yielded a peak at $4.2 \mathrm{~min}$, which coeluted with authentic 4SC and had the same UV spectrum as the standard ( $\mathrm{pH} \mathrm{6}$; see the legend to Fig. 4). Cochromatography of the unknown with $4 \mathrm{SC}$ was also observed on a reversed-phase column, where the (different) UV spectrum at pH 2 was identical for the unknown and the standard. A portion of the unknown was separated by HPLC and collected, and its UV spectrum was analyzed at $\mathrm{pH} 13$. We thus have five properties which together identify the unknown as 4SC.

With improved aeration, the growth of strain SPB1 was found to accelerate to reach a specific growth rate of $0.28 \mathrm{~h}^{-1}$ (Fig. 3a). After about $32 \mathrm{~h}$, the growth rate decreased to about $0.016 \mathrm{~h}^{-1}$ for about one generation. The first phase of growth was essentially concomitant with the disappearance of $R$-SPB and with the formation of sulfate; the transient excretion of 4SC was very limited (Fig. 3b). The molar growth yield was $6 \mathrm{~g}$ of protein/mol of $\mathrm{C}$. The second growth phase involved quantitative utilization of $S$-SPB and was concomitant with the release of sulfonate-sulfur as sulfate (Fig. 3b). The molar growth yield in this phase of growth was about $4 \mathrm{~g}$ of protein/ mol of $\mathrm{C}$, lower than the yield observed in the first phase but in the normal range (5). An unknown product was excreted in this phase $\left(\lambda_{\max }, 201 \mathrm{~nm} ; \lambda_{\min }, 222 \mathrm{~nm} ; \lambda_{\max }, 228 \mathrm{~nm} ; \lambda_{\min }, 251\right.$ $\mathrm{nm} ; \lambda_{\max }, 283 \mathrm{~nm}$; retention time on the chiral column, 6.5 $\min$ ), but as the residual dissolved organic carbon was negligible (about $2 \%$ of the original carbon, corrected for the carbon in solution after growth with 4-hydroxybenzoate), we did not examine it further.

In similar growth experiments on a smaller scale with racemic SPB-salts medium or $R$-SPB- or $S$-SPB-salts medium, growth was observed in each case. Growth with $R$-SPB was accompanied by transient excretion of 4SC, as shown in Fig. 2. The $R$-SPB-dependent specific activity of oxygen uptake in whole cells reached a maximum well before the end of growth, whereas the specific activity of 4SC-dependent oxygen uptake was stable during the growth phases. The $R$-SPB-containing reaction mixtures in the oxygen electrode displayed an accumulation of 4SC, which was detected by HPLC. Growth of strain SPB1 in $S$-SPB-salts medium was apparently faster than in the second phase of growth in racemic SPB-salts medium, but no 4SC was excreted. Reaction mixtures with $S$-SPB-grown cells in the oxygen electrode accumulated 4SC from $S$-SPB to concentrations about 10 -fold higher than the impurity with $R$-SPB, so $4 \mathrm{SC}$ is also an intermediate in the degradation of $S$-SPB.

Sulfite, the normal leaving group formed upon the degrada-
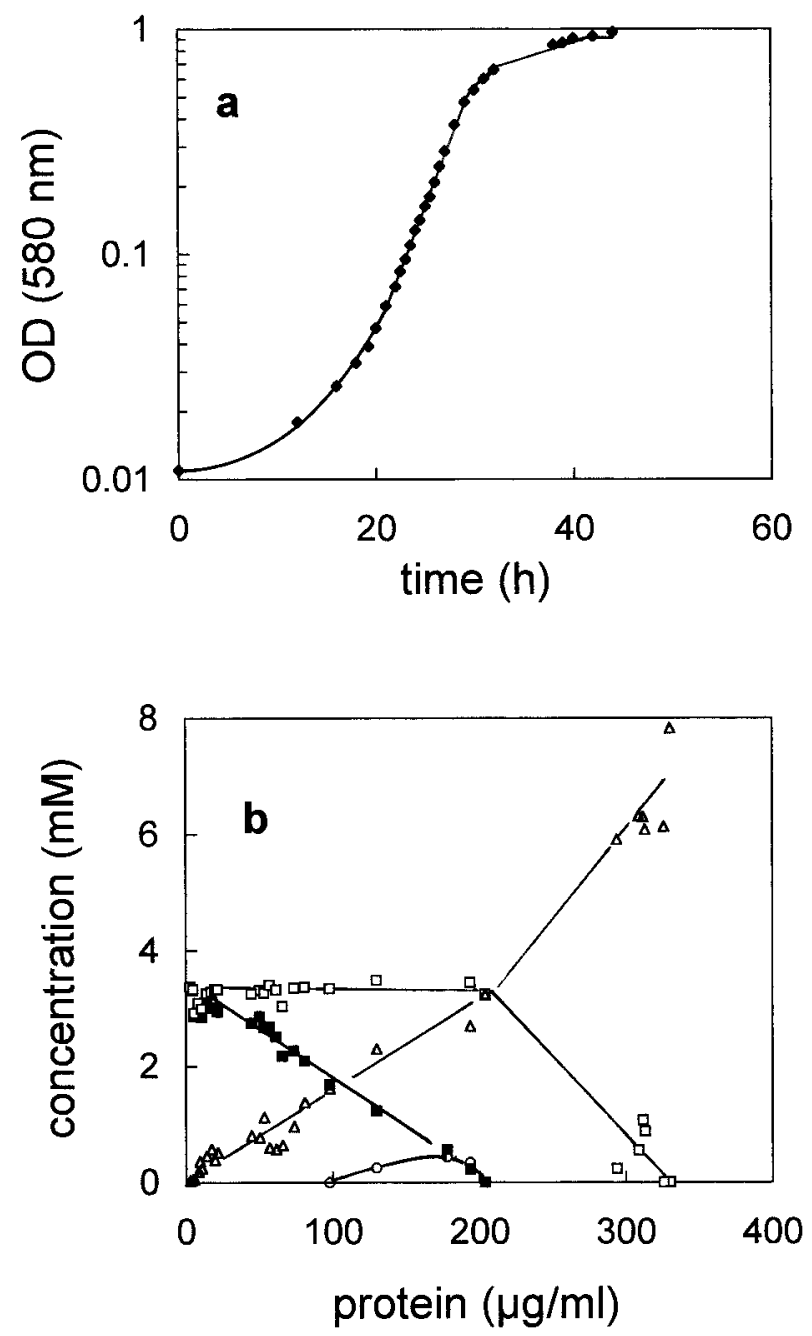

FIG. 3. Growth of D. acidovorans SPB1 with racemic SPB. Growth is shown in a conventional semilogarithmic plot (OD, optical density) (a) and in a linearized plot of the concentrations of substrates and products as a function of growth (b). Turbidity, $\diamond ; R$-SPB, $\mathbf{\square} ; S$-SPB, $\square$; 4SC, $\bigcirc$; sulfate, $\triangle$.

tion of sulfonates (7), was not detected during growth with racemic SPB. We presume there to be a sulfite oxidase which converts sulfite (perhaps intracellularly) to sulfate.

We examined the behavior of the mixed cultures SPB2 and SPB3 in SPB-salts medium. Utilization of both enantiomers was found in each case.

Ring cleavage of $4 \mathrm{SC}$ in crude extracts. Extracts of cells growing with $R$-SPB degraded 4SC (Fig. 4). No yellow color, which might indicate a meta cleavage, was detected, so we explored the possible presence of the ortho cleavage pathway, which was established by Feigel and Knackmuss (13). The pattern of biotransformation of 4SC (Fig. 4) is identical with that previously observed by Feigel (11). Samples taken during similar reactions and examined by reversed-phase HPLC showed the disappearance of the 4SC peak (at $2.2 \mathrm{~min}$ ) and the appearance of a novel peak (at $1.9 \mathrm{~min}$ ). In acidified samples, the novel peak disappeared and was replaced by another peak (at $2.1 \mathrm{~min}$ ). This resembles the description of Contzen et al. (2), who found the elution of 3-sulfo-cis,cis-muconate prior to that of 4SC during reversed-phase HPLC and, after acidification, the spontaneous formation of the corresponding lactone, 


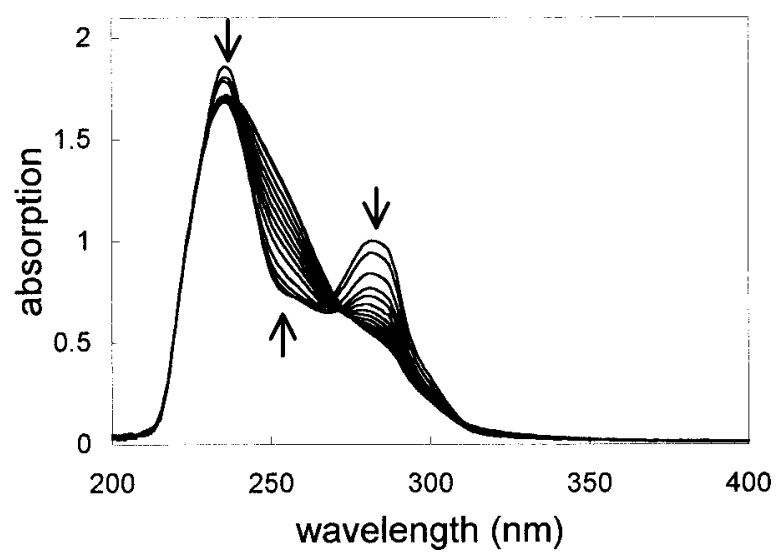

FIG. 4. UV spectra of the transformation of $4 \mathrm{SC}$ by crude extract of $D$. acidovorans SPB1. Spectra were taken at intervals; arrows pointing up or down indicate whether the absorption was increasing or decreasing. These conditions mask some of the spectral properties of 4SC. In our hands, 4SC at pH 2 displayed a maximum at low wavelengths $\left(\lambda_{\min }, 217 \mathrm{~nm} ; \lambda_{\max }, 233 \mathrm{~nm} ; \lambda_{\min }, 255 \mathrm{~nm} ; \lambda_{\max }\right.$, $279 \mathrm{~nm})$. At $\mathrm{pH} 6$ the maximum at low wavelengths was accompanied by values of $\lambda_{\min }, 226 ; \lambda_{\max }, 234 ; \lambda_{\min }, 267$; and $\lambda_{\max }, 282 \mathrm{~nm}$. At $\mathrm{pH} 13$ the maximum at low wavelengths was accompanied by values of $\lambda_{\min }, 243 \mathrm{~nm} ; \lambda_{\max }, 266 \mathrm{~nm} ; \lambda_{\min }$, $285 \mathrm{~nm}$; and $\lambda_{\max }, 303 \mathrm{~nm}$, similar to published data (48).

which had a longer retention time. The short retention times and interference from material in the enzyme assay made the measurement of UV spectra unsatisfactory, so we repeated the analyses on the chiral column. Our putative 3-sulfo-cis,cismuconate coeluted (at $3.4 \mathrm{~min}$ ) with authentic material from extracts of $H$. palleronii $\mathrm{S} 1$ and $A$. radiobacter $\mathrm{S} 2$, and both samples had the same UV spectrum in the diode array detector (a single maximum at $206 \mathrm{~nm}$ ). Our putative lactone coeluted (at $4.1 \mathrm{~min}$ ) with authentic material generated from the authentic sulfomuconate, and both samples had the same UV spectrum (with a maximum at $215 \mathrm{~nm}$ ).

Substrate range of $\boldsymbol{D}$. acidovorans SPB1. Strain SPB1 was able to grow with 4-hydroxybenzoate $(6 \mathrm{mM})$ and 3,4-dihydroxybenzoate $(3 \mathrm{mM})$ but not with 4 -methylbenzoate $(3 \mathrm{mM})$. The organism was found to utilize SPB, 4SC (3 $\mathrm{mM})$, and 4-(1-octyl)benzenesulfonate $(1 \mathrm{mM})$. There was no growth with 4-hydroxybenzenesulfonate $(3 \mathrm{mM})$, 4-carboxybenzenesulfonate $(3 \mathrm{mM})$, 4-methylbenzenesulfonate ( $3 \mathrm{mM})$, or commercial LAS $(0.5 \mathrm{mM})$. With commercial LAS, the further addition of 4-hydroxybenzoate allowed growth but did not alter the foaming of the LAS, which obviously was not degraded.

A complex mixture of unidentified sulfophenylcarboxylate intermediates from the degradation of commercial LAS was collected. These compounds were not significantly degraded by strain SPB1, which did grow in their presence if a suitable carbon source was supplied. Sulfophenylcarboxylates were thus not toxic to this strain; they were simply not growth substrates. The mixed cultures SPB2 and SPB3 were capable of slight growth with the mixture of sulfophenylcarboxylates, but the disappearance of only one peak was detected in each case, so these organisms also have a narrow substrate range for sulfophenylcarboxylates.

\section{DISCUSSION}

The worldwide degradation of SPB, an intermediate from the degradation of LAS, has been implicitly recognized for many years (e.g., see references 17 and 43) and demonstrated directly in material from sewage works (e.g., see reference 27), so the isolation of a bacterium, $D$. acidovorans SPB1, able to degrade the compound is not surprising. What has been less widely considered is the importance of the chirality of molecules like SPB (Fig. 1 and 3), as emphasized by Kohler and coworkers $(24,50)$. Given that the subterminal substitution of alkanes is normal not only in LAS surfactants but also in the widespread secondary alkanesulfonate surfactants (30), the supposedly facile degradation of common household products is more complex than previously realized.

Growth of $D$. acidovorans SPB1, certainly with the $R$ enantiomer, gives a normal value for the molar growth yield, which means a mass balance for carbon (see reference 3 ) as well as a mass balance for the sulfonate moiety (Fig. 3b). Utilization of the second enantiomer was initially not reproducible, and we attribute this to poor aeration, because improved aeration of flask cultures allowed full utilization of the second enantiomer with mass balance for the sulfonate moiety as sulfate (Fig. 3b). The growth yield with the second enantiomer was lower than that with the first, but as there was negligible residual carbon in the medium at the end of growth we presume the difference in yields to be facile, for example due to the increased contribution of maintenance energy to the energy budget at the lower growth rate (1). We also presume that an oxygenase attacking, e.g., $S$-SPB has a poor $K_{m}$ for oxygen.

The growth yield, especially with $R$-SPB, indicates that all the carbon atoms in the compound are utilized for growth. Thus the side chain, as well as the ring, must be processed through the amphibolic pathways to generate carbon skeletons for biosynthesis and conservation of energy. We have, as yet, no information on the pathway involved in utilization of the side chain.

We presume the degradation of $R$ - and $S$-SPB to be initiated by transport of these charged compounds across the cell membrane (see reference 7), and we hypothesize one transport system per enantiomer (see reference 50). The metabolism of the enantiomers converges at $4 \mathrm{SC}$, because this compound is observed as a transient intermediate during growth with $R$-SPB (Fig. 3b) and in suspensions of cells from cultures utilizing $S$-SPB. We do not yet know how these compounds are converted to $4 \mathrm{SC}$, whether in one novel dioxygenation or in several steps. We do, however, know that $4 \mathrm{SC}$ is degraded via the ortho cleavage pathway established for sulfanilate and benzene 1,3disulfonate $(2,13)$ (Fig. 4). This new example of 4SC functioning as a point of convergence of metabolic pathways and as the substrate for ring cleavage points out the general importance of the previous work $(2,13)$, especially if the degradation of LAS is always channeled through this pathway.

This is the first pathway for the degradation of sulfophenylcarboxylate(s) from commercial LAS to be proposed with direct evidence from work with a pure culture. Many hypothetical pathways can be found in the literature (e.g., see references 37, 38, 43, 47, and 49), but none involves 4SC. When more isolates are available, we will be able to see whether any of the old hypotheses are correct.

One major dichotomy found in the literature on LAS is whether pure cultures can degrade LAS (49) or whether communities are needed (21, 41; see also reference 19$)$. We suspect the difference lies in the LAS used. Commercial LAS is complex (see the introduction and Fig. 1) and is used by those who have found communities to be needed for complete degradation $(10,21,41)$. Model LAS is commercially available as single compounds [e.g., 1-(4-sulfophenyl)octane], each a terminally substituted alkane, whereas commercial LAS is always subterminally substituted (Fig. 1). The published work which illustrates pure cultures (49) seems to involves model LAS. The isolate used in this paper, $D$. acidovorans SPB1, utilizes model LAS but not commercial LAS. So, we presume that the me- 
tabolism of model LAS need not represent metabolism of commercial LAS. We have now isolated a heterotrophic bacterium which utilizes commercial LAS and concomitantly excretes sulfophenylcarboxylates of intermediate length (36a). Hrsak and Begonja (19), with a methanotroph catalyzing the oxygenation of commercial LAS to a sulfophenylcarboxylate of the same chain length, required a tier of heterotrophic organisms to generate compounds analogous to SPB. We presume that communities are generally required to degrade commercial LAS completely, as indicated elsewhere $(21,41)$.

The organism we isolated to degrade SPB, D. acidovorans SPB1, represents organisms widespread in soil and water, so the degradative pathway could be widespread in this species, or perhaps it is readily spread by horizontal gene transfer. Strain SPB1 has, however, a narrow substrate range for sulfophenylcarboxylates. Many intermediate mono- and dicarboxylated sulfophenyl moieties can be expected from LAS $(9,14,17)$, yielding theoretically seven sulfophenylcarboxylates of minimal length, so if only organisms with a narrow substrate range degrade these compounds, the complexity of communities degrading LAS must be considerable. There are three pathways known to degrade 4-toluenesulfonate (7), so given that a higher tonnage of LAS is degraded annually (see the introduction), it is perfectly possible that other ring cleavage pathways are also involved.

\section{ACKNOWLEDGMENTS}

We are grateful to N. Heeb (EMPA, Dübendorf, Switzerland) for providing the mass spectra and to E.-M. Schäfer for performing experiments in crude extracts. Bodensee Wasserversorgung (Sipplingen, Germany) kindly did the dissolved organic carbon analyses.

This work was supported by the University of Konstanz and ECOSOL, Brussels, Belgium. W.D. was supported by an exchange studentship from the China-Gesellschaft EV.

\section{REFERENCES}

1. Caldwell, D. R. 1995. Microbial physiology and metabolism. Wm. C. Brown, Dubuque, Iowa.

2. Contzen, M., R.-M. Wittich, H.-J. Knackmuss, and A. Stolz. 1996. Degradation of benzene 1,3-disulfonate by a mixed bacterial culture. FEMS Microbiol. Lett. 136:45-50.

3. Cook, A. M. 1987. Biodegradation of $s$-triazine xenobiotics. FEMS Microbiol. Rev. 46:93-116.

4. Cook, A. M. 1998. Sulfonated surfactants and related compounds: facets of their desulfonation by aerobic and anaerobic bacteria. Tenside Surfactants Deterg. 35:52-56.

5. Cook, A. M., H. Grossenbacher, and R. Hütter. 1983. Isolation and cultivation of microbes with biodegradative potential. Experientia 39:1191-1198.

6. Cook, A. M., and R. Hütter. 1981. s-Triazines as nitrogen sources for bacteria. J. Agric. Food Chem. 29:1135-1143.

7. Cook, A. M., H. Laue, and F. Junker. 1998. Microbial desulfonation. FEMS Microbiol. Rev. 22:399-419.

8. Denger, K., M. A. Kertesz, E. H. Vock, R. Schön, A. Mägli, and A. M. Cook. 1996. Anaerobic desulfonation of 4-tolylsulfonate and 2-(4-sulfophenyl)butyrate by a Clostridium sp. Appl. Environ. Microbiol. 62:1526-1530.

9. di Corcia, A., R. Samperi, and A. Marcomini. 1994. Monitoring aromatic surfactants and their biodegradation intermediates in raw and treated sewages by solid-phase extraction and liquid chromatography. Environ. Sci. Technol. 28:850-858.

10. Dong, W., S. Schulz, D. Schleheck, and A. M. Cook. 1999. Characterised reactions in aerobic and anaerobic utilisation of linear alkylbenzenesulfonate (LAS). Focus on biotechnology. Kluwer Academic, Dordrecht, The Netherlands.

11. Feigel, B. 1990. Synergistischer Abbau von 4-Aminobenzolsulfonat durch Hydrogenophaga palleronii und Agrobacterium radiobacter. Ph.D. thesis. University of Stuttgart, Stuttgart, Germany.

12. Feigel, B. J., and H.-J. Knackmuss. 1988. Bacterial catabolism of sulfanilic acid via catechol-4-sulfonic acid. FEMS Microbiol. Lett. 55:113-118.

13. Feigel, B. J., and H.-J. Knackmuss. 1993. Syntrophic interactions during degradation of 4-aminobenzenesulfonic acid by a two species bacterial culture. Arch. Microbiol. 159:124-130.

14. Field, J. A., J. A. Leenheer, K. A. Thorn, L. B. Barber, C. Rostad, D. L. Macalady, and S. R. Daniel. 1992. Identification of persistent anionic sur- factant-derived chemicals in sewage effluent and groundwater. J. Contam. Hydrol. 9:55-78.

15. Gesellschaft Deutscher Chemiker. 1996. German standard methods for the laboratory examination of water, waste water and sludge. $\mathrm{VCH}$, Weinheim, Germany.

16. Giger, W., A. C. Alder, P. H. Brunner, A. Marcomini, and H. Siegrist. 1989. Behaviour of LAS in sewage and sludge treatment and in sludge-treated soil. Tenside Surfactants Deterg. 26:95-100.

17. González-Mazo, E., M. Honing, D. Barceló, and A. Gómez-Parra. 1997. Monitoring long-chain intermediate products from the degradation of linear alkylbenzene sulfonates in the marine environment by solid-phase extraction followed by liquid chromatography/ionspray mass spectrometry. Environ. Sci. Technol. 31:504-510.

18. Hammer, A., A. Stolz, and H.-J. Knackmuss. 1996. Purification and characterization of a novel type of protocatechuate 3,4-dioxygenase with the ability to oxidize 4-sulfocatechol. Arch. Microbiol. 166:92-100.

19. Hrsak, D., and A. Begonja. 1998. Growth characteristics and metabolic activities of the methanotrophic-heterotrophic groundwater community. J. Appl. Microbiol. 85:448-456.

20. Hrsak, D., and D. Grbic-Galic. 1995. Biodegradation of linear alkylbenzenesulfonates (LAS) by mixed methanotrophic-heterotrophic cultures. J. Appl. Bacteriol. 78:487-494.

21. Jiménez, L., A. Breen, N. Thomas, T. W. Federle, and G. S. Sayler. 1991. Mineralization of linear alkylbenzene sulfonate by a four-member aerobic bacterial consortium. Appl. Environ. Microbiol. 75:1566-1569.

22. Junker, F., J. A. Field, F. Bangerter, K. Ramsteiner, H.-P. Kohler, C. L. Joannou, J. R. Mason, T. Leisinger, and A. M. Cook. 1994. Oxygenation and spontaneous deamination of 2-aminobenzenesulphonic acid in Alcaligenes sp. strain O-1 with subsequent meta ring cleavage and spontaneous desulphonation to 2-hydroxymuconic acid. Biochem. J. 300:429-436.

23. Junker, F., T. Leisinger, and A. M. Cook. 1994. 3-Sulphocatechol 2,3-dioxygenase and other dioxygenases (EC 1.13.11.2 and EC 1.14.12.-) in the degradative pathways of 2-aminobenzenesulphonic, benzenesulphonic and 4-toluenesulphonic acids in Alcaligenes sp. strain O-1. Microbiology (Reading, U.K.) 140:1713-1722

24. Kanz, C., M. Nölke, T. Fleischmann, H.-P. E. Kohler, and W. Giger. 1998. Separation of chiral biodegradation intermediates of linear alkylbenzenesulfonates by capillary electrophoresis. Anal. Chem. 70:913-917.

25. Kohler, H.-P. E., W. Angst, W. Giger, C. Kanz, S. Müller, and M. J.-F. Suter. 1997. Environmental fate of chiral pollutants-the necessity of considering stereochemistry. Chimia 51:947-951.

26. Kölbener, P., U. Baumann, T. Leisinger, and A. M. Cook. 1995. Linear alkylbenzenesulfonate (LAS) surfactants in a simple test to detect refractory organic carbon (ROC): attribution of recalcitrants to impurities in LAS. Environ. Toxicol. Chem. 14:571-577.

27. Kölbener, P., U. Baumann, T. Leisinger, and A. M. Cook. 1995. Non-degraded metabolites arising from the biodegradation of commercial linear alkylbenzenesulfonate (LAS) surfactants in a laboratory trickling filter. Environ. Toxicol. Chem. 14:561-569.

28. Kölbener, P., A. Ritter, F. Corradini, U. Baumann, and A. M. Cook. 1996. Refractory organic carbon and sulfur in the biotransformed by-products in commercial linear alkylbenzenesulfonate (LAS): identifications of arylsulfonates. Tenside Surfactants Deterg. 33:149-156.

29. Kondo, H., M. Yazawa, M. Enami, and M. Ishimoto. 1982. Sulfite production from benzenesulfonate by bacterial enzyme compared with taurine. Ganryu Aminosan 5:237-242.

30. Kosswig, K. 1993. Herstellung, Eigenschaften und Verwendung von Tensiden, p. 115-177. In K. Kosswig and H. Stache (ed.), Die Tenside. Carl Hanser Verlag, Munich, Germany.

31. Kosswig, K. 1994. Surfactants, p. 747-817. In W. Gerhartz and B. Elvers (ed.), Ullmann's encyclopedia of industrial chemistry, 5th ed., vol. A25. VCH, Weinheim, Germany.

32. Laue, H., J. A. Field, and A. M. Cook. 1996. Bacterial desulfonation of the ethanesulfonate metabolite of the chloroacetanilide herbicide metazachlor. Environ. Sci. Technol. 30:1129-1132.

33. Maidak, B. L., G. J. Olsen, N. Larsen, R. Overbeek, M. J. McCaughey, and C. R. Woese. 1996. The ribosomal database project (RDP). Nucleic Acids Res. 24:82-85.

34. Marcomini, A., A. Di Corcia, R. Samperi, and S. Capri. 1993. Reversedphase high-performance liquid chromatographic determination of linear alkylbenzene sulfonates, nonylphenol polyethoxylates and their carboxylic biotransformation products. J. Chromatogr. 644:59-71.

35. Matthijs, E., M. S. Holt, A. Kiewiet, and G. B. J. Rijs. 1997. Fate of surfactants in activated sludge waste water treatment plants: outcome of field studies. Tenside Surfactants Deterg. 34:238-241.

36. Rainey, F. A., N. Ward-Rainey, R. M. Kroppenstedt, and E. Stackebrandt. 1996. The genus Nocardiopsis represents a phylogenetically coherent taxon and a distinct actinomycete lineage: proposal of Nocardiopsaceae fam. nov. Int. J. Syst. Bacteriol. 46:1088-1092.

36a.Schleheck, D., W. Dong, K. Denger, E. Heinzle, and A. M. Cook. 2000. An $\alpha$-proteobacterium converts linear alkylbenzensulfonate surfactants into sulfophenylcarboxylates and linear alkyldiphenyletherdisulfonate surfactants 
into sulfodiphenylethercarboxylates. Appl. Environ. Microbiol. 66:1911-1916.

37. Schöberl, P. 1989. Basic principles of LAS biodegradation. Tenside Surfactants Deterg. 26:86-94.

38. Schöberl, P. 1993. Biologischer Tensid-Abbau, p. 407-464. In K. Kosswig and H. Stache (ed.), Die Tenside. Carl Hanser Verlag, Munich, Germany.

39. Schöberl, P. 1997. Linear alkylbenzenesulphonate (LAS) monitoring in Germany. Tenside Surfactants Deterg. 34:233-237.

40. Schulz, K. 1996. Der westeuropäische Tensidmarkt 1994/1995. Tenside Surfactants Deterg. 33:94-95.

41. Sigoillot, J.-C., and M.-H. Nguyen. 1992. Complete oxidation of linear alkylbenzene sulfonate by bacterial communities selected from coastal seawater. Appl. Environ. Microbiol. 58:1308-1312.

42. Smibert, R. M., and N. R. Krieg. 1994. Phenotypic characterization, p. 607-654. In P. Gerhardt, R. G. E. Murray, W. A. Wood, and N. R. Krieg (ed.), Methods for general and molecular bacteriology. American Society for Microbiology, Washington, D.C.

43. Swisher, R. D. 1987. Surfactant biodegradation, 2nd ed. Marcel Dekker, New York, N.Y.

44. Tabatabai, M. A. 1974. Determination of sulfate in water sample. Sulphur
Inst. J. 10:11-13.

45. Taylor, P. W., and G. Nickless. 1979. Paired-ion high-performance liquid chromatography of partially biodegraded linear alkylbenzenesulphonate. J. Chromatogr. 178:259-269.

46. Thurnheer, T., T. Köhler, A. M. Cook, and T. Leisinger. 1986. Orthanilic acid and analogues as carbon sources for bacteria: growth physiology and enzymatic desulphonation. J. Gen. Microbiol. 132:1215-1220.

47. Wagner, G. 1997. Waschmittel: Chemie and Ökologie, 2nd ed. Klett Verlag, Stuttgart, Germany.

48. Westervelt, H. H., W. J. Frederick, E. W. Malcom, and D. B. Easty. 1982. The determination and temperature-dependence of the calcium-catechol-4-sulfonate complex in alkaline aqueous media. Anal. Chim. Acta 138:237-243.

49. White, G. F., and N. J. Russell. 1994. Biodegradation of anionic surfactants and related molecules, p. 143-177. In C. Ratledge (ed.), Biochemistry of microbial degradation. Kluwer, Dordrecht, The Netherlands.

50. Zipper, C., M. Bunk, A. J. B. Zehnder, and H.-P. E. Kohler. 1998. Enantioselective uptake and degradation of the chiral herbicide dichlorprop $[(R S)$ 2-(2,4-dichlorophenoxy)propanoic acid] by Sphingomonas herbicidovorans MH. J. Bacteriol. 180:3368-3374. 